\title{
Development of Neonatal Murine Microglia In Vitro: Changes in Response to Lipopolysaccharide and Ischemia-Like Injury
}

\author{
VALERIE Y. CHOCK AND RONA G. GIFFARD \\ Department of Neonatology [V.Y.C.], Stanford University School of Medicine, Stanford, California 94305; \\ and Department of Anesthesia [R.G.G.], Stanford University School of Medicine, Stanford, California 94305
}

\begin{tabular}{|c|c|}
\hline \multicolumn{2}{|c|}{ ABSTRACT } \\
\hline $\begin{array}{l}\text { Hypoxic/ischemic brain injury in the neonate can activate an } \\
\text { inflammatory cascade, which potentiates cellular injury. The role } \\
\text { of microglia in this inflammatory response has not been studied } \\
\text { extensively. We used an in vitro model of murine microglia to } \\
\text { investigate changes in microglial cytokine release and injury } \\
\text { during early development. Isolated microglia were subjected to } \\
\text { lipopolysaccharide (LPS) activation or injury by glucose depri- } \\
\text { vation (GD), serum deprivation (SD), or combined oxygen- } \\
\text { glucose deprivation (OGD) for varying durations. The extent and } \\
\text { the type of cell death were determined by trypan blue, terminal } \\
\text { deoxynucleotidyl end-nick labeling, and annexin staining. Early- } \\
\text { culture microglia ( } 2-3 \text { d in purified culture) showed significantly } \\
\text { more apoptotic cell death after SD, GD, and OGD compared with } \\
\text { microglia maintained in culture for } 14-17 \text { d. Measurements of } \\
\text { tumor necrosis factor- } \alpha \text { (TNF- } \alpha \text { ) and IL-1 } \beta \text { in culture media } \\
\text { demonstrated that OGD induced greater release of both TNF- } \alpha \\
\text { and IL- } 1 \beta \text { than LPS activation, with early-culture microglia } \\
\text { producing more TNF- } \alpha \text { compared with late-culture microglia. }\end{array}$ & $\begin{array}{l}\quad \text { Abbreviations } \\
\text { DIV, day in vitro } \\
\text { GD, glucose deprivation } \\
\text { LPS, lipopolysaccharide } \\
\text { OGD, oxygen glucose deprivation } \\
\text { PI, propidium iodide } \\
\text { SD, serum deprivation } \\
\text { TNF- } \alpha \text {, tumor necrosis factor- } \alpha \\
\text { TUNEL, terminal deoxynucleotidyl end-nick labeling }\end{array}$ \\
\hline
\end{tabular}

Neonatal hypoxic/ischemic brain injury causes significant long-term neurologic morbidity in survivors. Deleterious outcomes include cerebral palsy, mental retardation, and cognitive and behavioral dysfunction. Hypoxia and ischemia can occur with birth asphyxia or prenatally with chronic placental vascular insufficiency and fluctuations in cerebral blood flow. Another factor that contributes to brain injury is infection and inflammation. Maternal chorioamnionitis, whether acute or subclinical, has been associated with a 9-fold increased risk for cerebral palsy (1).

Received May 20, 2004; accepted August 30, 2004.

Correspondence: Rona G. Giffard, M.D., Ph.D., Department of Anesthesia, Room S-272, Stanford University Medical Center, Stanford, CA 94305-5123; e-mail: rona.giffard@stanford.edu.

DOI: 10.1203/01.PDR.0000155758.79523.44
Recently, the contribution of inflammation to hypoxic/ ischemic brain injury has been recognized. Microglia, or resident brain macrophages, are the major inflammatory cell type in the CNS. Upon activation, they release proinflammatory cytokines, oxygen free radicals, and nitric oxide and can stimulate astrocytes to do the same $(2,3)$. The release of cytokines from activated microglia may further exacerbate neuronal injury, whereas inhibition of tumor necrosis factor- $\alpha$ (TNF- $\alpha$ ) reduces neuronal death in vitro and in vivo $(4,5)$. The potentiation of hypoxic/ischemic injury by inflammation is a significant therapeutic target in adult cerebral ischemia $(6,7)$ that has not been studied extensively in the perinatal setting.

Sensitivity to hypoxic/ischemic injury is known to change with development. Data from the National Collaborative Perinatal Project showed that periventricular leukomalacia peaked 
at $32-35 \mathrm{wk}$ gestation, whereas hypertrophic astrocytes peaked at 36-44 wk gestation (8). Early differentiating oligodendrocytes were shown to be more vulnerable to free radical injury and cytokine injury compared with mature oligodendrocytes $(9,10)$.

Whether microglia also have a maturation-dependent response to injury is unknown, so we determined the vulnerability of microglia to ischemia-like injury and their response to an inflammatory stimulus as a function of age in culture. Microglia that were isolated from newborn mouse brain were challenged with glucose deprivation (GD), serum deprivation (SD), or oxygen-glucose deprivation (OGD). Cell death, cytokine release, and extent of apoptosis were measured after increasing durations in culture. A preliminary report has appeared (11).

\section{METHODS}

Microglial cultures. Cultures were prepared as described previously by us and others $(12-14)$ by shaking off from mixed glial cultures. In brief, mixed glial cultures were prepared from postnatal day 1-3 Swiss Webster mice (Simonsen, Gilroy, CA) according to a protocol approved by the Stanford University Animal Care and Use Committee. Animals were anesthetized before decapitation, and cerebral hemispheres were removed and freed of meninges. Minced pooled tissue was treated with $0.25 \%$ trypsin, centrifuged, and dissociated into a single-cell suspension by gentle trituration. Cells were plated at a density of 2 hemispheres per $10 \mathrm{~mL}$ in Eagle's minimal essential medium (GIBCO, Grand Island, NY) supplemented with $10 \%$ equine serum (Hyclone, Logan, UT), 10\% fetal bovine serum (Hyclone), $21 \mathrm{mM}$ (final concentration) glucose (Sigma Chemical Co., St. Louis, MO), and $10 \mathrm{ng} / \mathrm{mL}$ epidermal growth factor (Sigma Chemical Co.) in flasks. Cells were incubated at $37^{\circ} \mathrm{C}$ in a $5 \% \mathrm{CO}_{2}$ incubator. Medium was changed on day in vitro (DIV) 2-3. Microglia were harvested from mixed glial cultures between DIV 7 and 14. After shaking at $160 \mathrm{rpm}$ for $30 \mathrm{~min}$ on an orbital shaker, medium from cultures was collected and centrifuged at $800 \times \mathrm{g}$ for $10 \mathrm{~min}$. Plates were coated with Collagen I (50 $\mu \mathrm{g} / \mathrm{mL}$; Sigma Chemical Co.) for $10 \mathrm{~min}$. Microglia were plated at a density of $3 \times 10^{5}$ cells $/ \mathrm{mL}$ in Eagle's minimal essential medium (GIBCO) supplemented with 5\% equine serum (Hyclone), 5\% fetal bovine serum (Hyclone), and $2 \mathrm{mM}$ glutamine. After $1 \mathrm{~h}$, wells were washed with medium to remove unattached astrocytes. Macrophage colonystimulating factor (Sigma Chemical Co.) then was added $(100 \mathrm{ng} / \mathrm{mL})$, and cells were used for experiments after 2-17 d.

This method yields cultures that contain $>99 \%$ microglia as determined by histochemical staining with Griffonia simplicifolia B4-isolectin (IB-4; Sigma Chemical Co.) and immunoreactivity for glial fibrillary acidic protein (Sigma Chemical Co.). On average, $1 \%$ of cells stained with the astrocyte marker glial fibrillary acidic protein; the remaining cells stained with IB-4 (14).

Injury paradigms. GD and combined OGD were performed as described previously (15). Microglial cultures were deprived of glucose by changing the culture medium to glucose-free balanced salt solution $\left(\mathrm{BSS}_{0}\right)$ at $\mathrm{pH} 7.4$ that contained $116 \mathrm{mM} \mathrm{NaCl}, 5.4 \mathrm{mM} \mathrm{KCl}, 1.8 \mathrm{mM} \mathrm{CaCl}_{2}, 0.8 \mathrm{mM} \mathrm{MgSO}_{4}, 1 \mathrm{mM}$ $\mathrm{NaH}_{2} \mathrm{PO}_{4}, 14.7 \mathrm{mM} \mathrm{NaHCO}, 10 \mathrm{mM}$ HEPES, and $10 \mathrm{mg} / \mathrm{L}$ phenol red. Microglial cultures were deprived of serum in the same way except that glucose was present at a concentration of $5.5 \mathrm{mM}$. Control cultures were washed into fresh growth medium. OGD was performed by exchanging medium for deoxygenated $\mathrm{BSS}_{0}$ in an anoxic chamber, $\mathrm{O}_{2}<0.02 \%$ (Coy Laboratory Products, Grass Lake, MI). After 18-24 h, cells were removed from the chamber, glucose was added to $5.5 \mathrm{mM}$, and cells were returned to the normoxic, $37^{\circ} \mathrm{C}$ incubator for $24 \mathrm{~h}$ to simulate reperfusion.

Quantification of cell death. Cultures were stained with $0.4 \%$ trypan blue (GIBCO) and counted using bright field illumination. At least 100 cells were counted per culture. The nonviable, trypan blue-positive cells were counted as a percentage of total cells present.

Apoptosis assays. Nuclear morphology was assessed as reported previously using Hoechst dye $(0.5 \mathrm{mg} / \mathrm{mL})$ for viable cells and propidium iodide (1 $\mathrm{mg} / \mathrm{mL}$; Sigma Chemical Co.) for nuclear staining of nonviable cells (16).

Terminal deoxynucleotidyl end-nick labeling (TUNEL) staining was performed using an in situ cell death detection kit (Roche, Mannheim, Germany) to label DNA strand breaks to identify apoptotic cells. Cultured microglia on DIV 3 were fixed with $4 \%$ paraformaldehyde in PBS $(10 \mathrm{mM}, \mathrm{pH} 7.4)$ for $1 \mathrm{~h}$ at room temperature, incubated with $3 \%$ hydrogen peroxide for $15 \mathrm{~min}$, and air dried. The fixed cells were permeabilized with $0.1 \%$ Triton X-100 for $2 \mathrm{~min}$ $\left(4^{\circ} \mathrm{C}\right)$ and then labeled with a mixture of terminal deoxynucleotidyl transferase and fluorescein tagged 2 -deoxyuridine $5^{\prime}$-triphosphate for $1 \mathrm{~h}$ at $37^{\circ} \mathrm{C}$, followed by reaction with horseradish peroxidase-conjugated anti-fluorescein antibody for $30 \mathrm{~min}$ to amplify the signal. DNAse (Invitrogen, Carlsbad, CA) was added to some cultures before staining as a positive control. Other positive controls were neuronal cultures deprived of serum for $24 \mathrm{~h}$. Labeling was visualized using diaminobenzidine (Sigma Chemical Co.), and cells were counted using bright field microscopy $(\times 40)$. Criteria for TUNEL-positive cells were intense staining coupled with fragmented or condensed and shrunken nuclei.

Annexin V staining of injured cells was performed after PBS wash by incubation for $15 \mathrm{~min}$ with Annexin V FITC reagent mixture and propidium iodide (PI) according to manufacturer's recommendations (Santa Cruz Biotechnology, Santa Cruz, CA). Labeled cells then were analyzed by fluorescence microscope and counted. Cells were considered apoptotic when they stained for annexin but not PI. Annexin-positive cells that were also PI staining could be either apoptotic or necrotic with access to phosphatidylserine on the inner leaflet of the membrane occurring as a result of breakdown of the plasma membrane. To avoid this possible confound, cultures were stained early after injury and analyzed before $>5 \%$ of the cells stained with PI. Serum-deprived young neurons were used as a positive apoptotic control; healthy cells were used as a negative control.

Activated caspase- 3 was assessed by immunohistochemistry as a biochemical marker of apoptosis. Cells were fixed with 50\% acetone/50\% methanol, incubated with $0.3 \%$ hydrogen peroxide to block endogenous peroxidases, and blocked with $2 \%$ goat serum to prevent nonspecific binding. Cells then were incubated with anti-active caspase-3 primary antibody at 1:1000 dilution (rabbit monoclonal; Pharmingen, San Diego, CA). Secondary antibody conjugated to horseradish peroxidase then was added. Neurons that were treated with serum deprivation for $24 \mathrm{~h}$ again were used as a positive control, and healthy cells were used as a negative control. Cells were exposed to $0.2 \mathrm{~mL}$ of diaminobenzidine substrate and counted under bright field microscopy $(\times 40$ objective) in four fields per well. Approximately 100 cells per well were counted.

LPS activation. Microglia were exposed to lipopolysaccharide (LPS; Escherichia coli serotype O55:B5; Sigma Chemical Co.) at a concentration of 10 $\mu \mathrm{g} / \mathrm{mL}$. This concentration was previously shown to activate murine microglia without causing cell death (14). Microglia that were cultured for 3 or $14 \mathrm{~d}$ were incubated for $24 \mathrm{~h}$ with LPS at $37^{\circ} \mathrm{C}$ in $5 \%$ serum growth media.

Cytokine assays. Culture supernatants after OGD injury or LPS activation were collected and saved at $-80^{\circ} \mathrm{C}$ until assayed. ELISA assays for TNF- $\alpha$ and IL-1B were run according to the manufacturer's instructions (BD Bioscience, San Diego, CA). Culture medium was added to 96-well plates followed by coating antibodies. TNF- $\alpha$ and IL- $1 \beta$ standards, blanks, and experimental conditions were run in parallel, in triplicate. Biotin-conjugated detection antibody was added and visualized by $3,3^{\prime} 5,5^{\prime}$-tetramethylbenzidine. Stop solution was added after $30 \mathrm{~min}$. Absorbance at $450 \mathrm{~nm}$ was measured on a SpectraMAX 340 plate reader (Molecular Devices, Sunnyvale, CA). Measurements were normalized to the amount of protein per well. Protein concentrations were determined using the bicinchoninic acid method (BCA protein assay; Bio-Rad, Hercules, CA).

Statistics. All data were analyzed and statistical significance was determined with $t$ test or ANOVA and Student Newman-Keuls test for multiple comparisons (SigmaStat; SPSS Science, Chicago, IL). A $p<0.05$ was considered significant.

\section{RESULTS}

Vulnerability to injury. Early-culture microglia (2-3 DIV) were more sensitive to GD compared with late-culture microglia (14-17 DIV; Fig. 1). By 18 h GD, 91.5\% of early microglia were dead by trypan blue staining compared with only $21.7 \%$ of late-culture microglia $(p<0.05)$. Early microglia were also significantly more sensitive to OGD compared with late microglia, showing nearly double the amount of cell death after 8 and $18 \mathrm{~h}(p<0.05$; Fig. 2). This difference disappeared by $24 \mathrm{~h}$ of OGD, when cell death was widespread at both ages. Early-culture microglia died to a greater extent after $24 \mathrm{~h}$ of SD compared with late-culture microglia (Fig. 3). After $18 \mathrm{~h}$ of SD, $28.8 \%$ cell death was observed for early microglia compared with $14 \%$ cell death for late microglia ( $p$ $<0.05)$. 


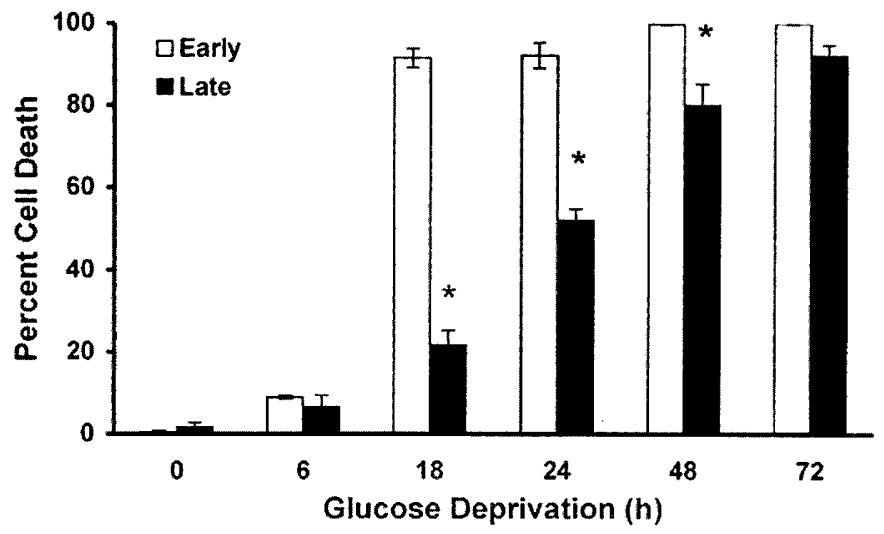

Figure 1. Early-culture microglia are more sensitive to GD. At time points between 18 and $48 \mathrm{~h}$ of GD, early-culture microglia (2-3 DIV) show significantly more cell death by trypan blue staining than late-culture microglia (14-17 DIV). Data shown are mean \pm SEM for $n=6-8$ cultures; ${ }^{*} p<0.05$ $v s$ early cultures at the same time point.

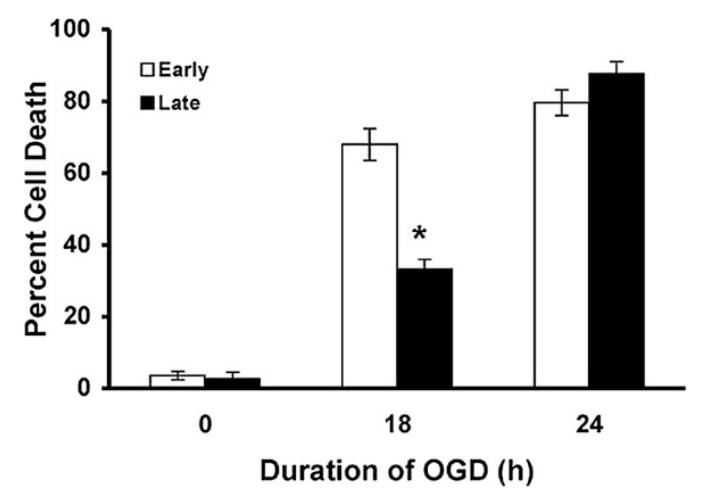

Figure 2. Early-culture microglia are more sensitive to OGD. By $18 \mathrm{~h}$ of OGD, early-culture microglia (2-3 DIV) show significantly more cell death by trypan blue staining than late-culture microglia (14-17 DIV). By $24 \mathrm{~h}$, this difference disappears as a result of nearly total cell death in both types of cultures. Data are mean \pm SEM for $n=8$ cultures; ${ }^{*} p<0.05 v$ s early cultures at the same time point.

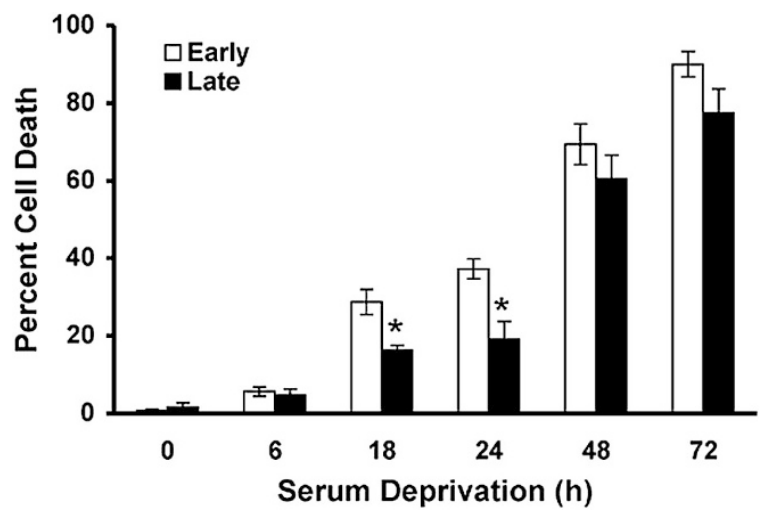

Figure 3. Early-culture microglia are more sensitive to SD. At time points between 18 and 24 h of SD, early-culture microglia (2-3 DIV) show significantly more cell death by trypan blue staining than late-culture microglia (14-17 DIV). ${ }^{*} p<0.05 v s$ early cultures at the same time point; data from $n$ $=6-8$ cultures. Microglia were less sensitive to SD than to either GD or OGD.

Type of cell death. To ascertain the type of cell death that occurs in microglia as a function of duration in culture, we used several assays for apoptosis. Nuclear morphology was observed after Hoechst and PI staining. Control microglia stained with Hoechst dye had discrete, round nuclei (Fig. 4A). After SD, GD, and OGD, nuclei of nonviable microglia stained with PI. Many nuclei were small, and characteristic apoptotic nuclear fragmentation was occasionally observed (Fig. 4B). TUNEL staining showed that the majority of early-culture microglia (DIV 3) were TUNEL positive with condensed nuclei after all three insults tested (Fig. 4C). Staining with annexin demonstrated that all injuries resulted in externalization of phosphatidylserine to the outer leaflet of the plasma membrane before membrane breakdown, an early sign of apoptosis (17) (Fig. 4D).

We also assayed for activated caspase-3, a known execution protease in apoptosis. Compared with control cultures, both early- and late-culture microglia (DIV 2 and DIV 14) were positive for activated caspase-3 after $24 \mathrm{~h}$ of OGD. There was no significant difference between early and late cultures in the number of caspase-3-positive cells after $24 \mathrm{~h}$ of OGD, an insult resulting in equivalent cell death (Fig. 5).

Cytokine release. To look for possible changes in inflammatory response of microglia with age, we measured cytokine release after OGD to correlate with age-related changes in microglial survival. Early-culture microglia (DIV 3) released more than twice as much TNF- $\alpha$ compared with late-culture microglia (DIV 14) after both 8 and 18 h of OGD. TNF- $\alpha$ release increased with longer durations of OGD, and the difference between early and late cultures was more pronounced after $18 \mathrm{~h}$ of OGD (Fig. 6A). There was a 10 -fold increase in IL- $1 \beta$ levels after OGD, but no significant difference in the release of IL- $1 \beta$ between early- and late-culture microglia was observed after injury (Table 1).

We also measured cytokine release after an inflammatory stimulus, exposure to LPS. Early-culture, LPS-stimulated microglia (DIV 3) released more than twice as much TNF- $\alpha$

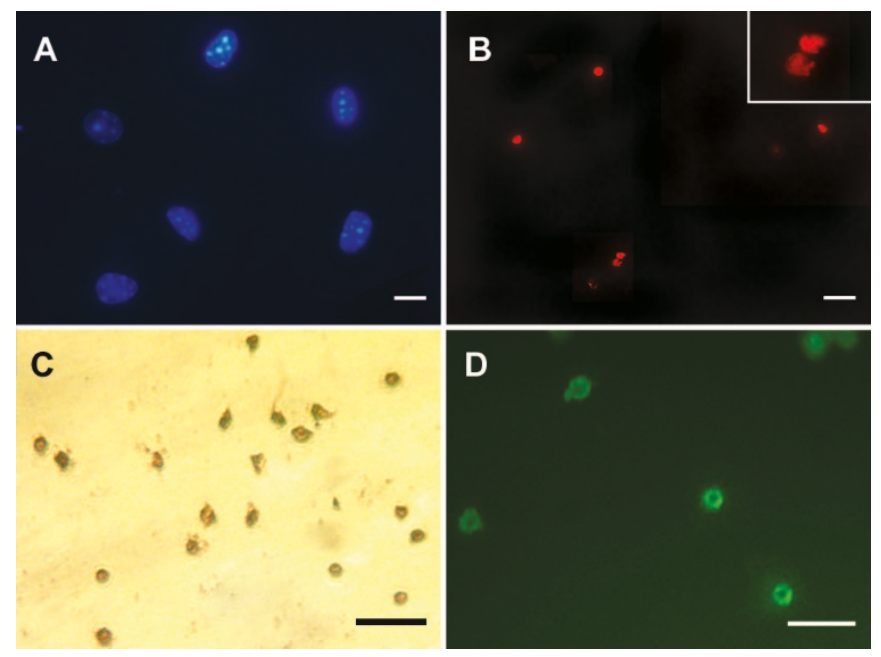

Figure 4. Photomicrographs of apoptotic microglia after OGD compared with control microglia. Hoechst and PI staining show discrete nuclei in viable microglia $(A)$ and condensed nuclei $(B)$ after $18 \mathrm{~h}$ of OGD. Scale bars $=10$ $\mu \mathrm{m}$. (C) TUNEL staining after $24 \mathrm{~h}$ of OGD shows small, condensed, and occasionally irregular nuclei with margination of chromatin. Scale bar $=20$ $\mu \mathrm{m}$. (D) Annexin staining of microglia after $8 \mathrm{~h}$ of OGD in early cultures. Scale bar $=20 \mu \mathrm{m}$. 


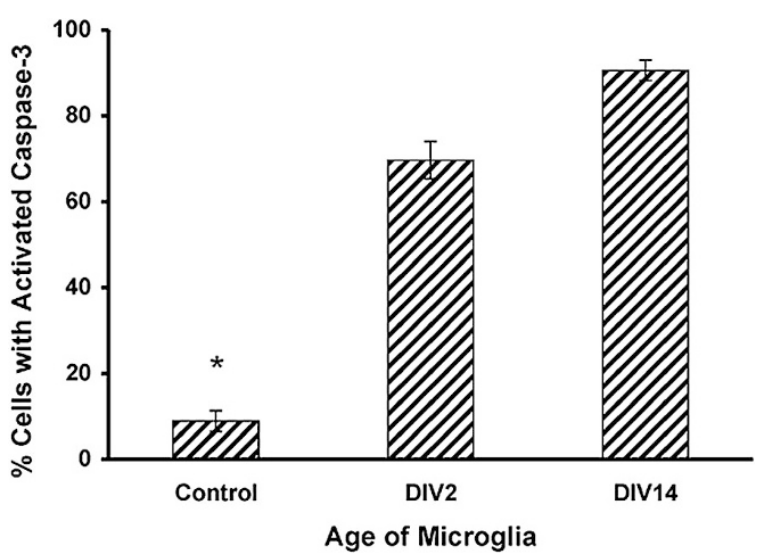

Figure 5. OGD results in activated caspase-3 staining of microglia. Activated caspase-3 is detected in both early- (DIV 2) and late-culture (DIV 14) microglia after $24 \mathrm{~h}$ of OGD compared with control microglia; ${ }^{*} p<0.05 v s$ both DIV 2 and DIV 14 for $n=3$ different cultures.
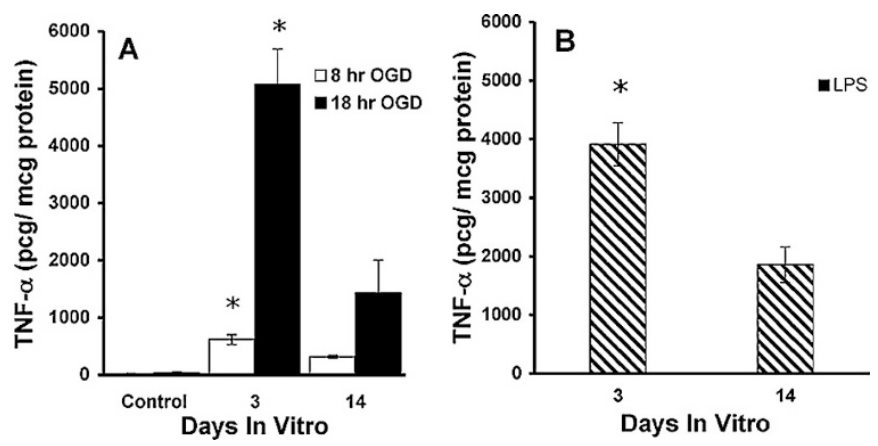

Figure 6. Early-culture microglia release more TNF- $\alpha$ after LPS activation and OGD. (A) After both 8 and $18 \mathrm{~h}$ of OGD, microglia at DIV 3 release significantly more TNF- $\alpha$ compared with late-culture microglia at DIV 14 . The amount of TNF- $\alpha$ release increased with longer durations of OGD, and the difference between early and late culture was more pronounced after $18 \mathrm{~h}$ of OGD. (B) Early cultures release more TNF- $\alpha$ after $10 \mu \mathrm{g} / \mathrm{mL}$ LPS activation for $24 \mathrm{~h}$. Levels of TNF- $\alpha$ are expressed in pcg/mcg protein for $n=4$ cultures; $* p<0.05$ vs late cultures.

Table 1. Microglia release $I L-1 \beta$ after LPS addition and $O G D$

\begin{tabular}{lcc}
\hline Condition & $\begin{array}{c}\text { Culture age } \\
(\mathrm{DIV})\end{array}$ & $\begin{array}{c}\mathrm{IL}-1 \beta \\
(\mathrm{pcg} / \mathrm{mcg} \text { protein } \pm \text { SEM })\end{array}$ \\
\hline Control & 2 & $35.6 \pm 12$ \\
Control & 14 & $40.2 \pm 7$ \\
LPS Addition & 2 & $110.7 \pm 9$ \\
LPS Addition & 14 & $94.3 \pm 13$ \\
OGD 18 h & 2 & $392.7 \pm 26$ \\
OGD 18 h & 14 & $431.6 \pm 68$ \\
\hline
\end{tabular}

(3909 pcg/mcg protein) as late-culture (DIV 14) microglia (1856 pcg/mcg protein; $p<0.05$; Fig. $6 B$ ). There was a 2-fold increase in IL- $1 \beta$ levels after LPS addition but no significant difference with age in culture (Table 1). LPS addition did not cause significant microglial cell death at either age in culture through $24 \mathrm{~h}$.

\section{DISCUSSION}

The importance of microglia and inflammation in brain injury is widely recognized. However, very little research has been done on the effects of development on microglial func- tion. Our results show that early-culture microglia are more vulnerable to stresses that simulate ischemia as well as to induction of apoptosis by loss of growth factors (SD). This decrease in vulnerability to injury with age in culture is similar to the response of oligodendrocytes (9) and contrasts with findings for neurons and astrocytes $(18,19)$.

The selective vulnerability of early-culture microglia may be due to immaturity of mechanisms that normally protect against stress. For example, impaired glucose and substrate utilization in the immature brain can further worsen hypoxic/ischemic injury in rats (20). Specifically relevant to activated microglia is their ability to manage oxidative stress given their innate production of nitric oxide and superoxide (21). It is possible that lower antioxidant levels in young microglia impair their ability to combat oxidative stress. Although specific changes in microglial antioxidant levels with age have yet to be described, it is known that several antioxidant enzymes overall are lower in immature neonatal rat brain than in adult brain $(22,23)$. Decreased glutathione stores and increased free iron in immature brain can also result in more free radical generation (24). This susceptibility to oxidative injury may also characterize developing microglia.

The mode of cell death was primarily apoptosis in both early- and late-culture microglia. The cultures demonstrated morphologic features consistent with apoptosis, including nuclear condensation and DNA fragmentation (by Hoechst/PI and TUNEL staining). Caspase-3 activation and externalization of phosphatidylserine residues before cell lysis were observed, also consistent with apoptosis. There was no significant difference in the extent of apoptosis with the type of injury or age of microglia in culture.

Microglial activation can lead to release of factors that contribute to neurotoxicity (25-28), a process that may be influenced by age. Therefore, we tested whether the inflammatory response mounted by microglia changed with time in our cultures. Baseline release of TNF- $\alpha$ or IL- $1 \beta$ did not vary with age. Both OGD and LPS markedly induced release of both cytokines. Whereas early-culture microglia exhibited increased TNF- $\alpha$ release compared with late-culture microglia, induced IL-1 $\beta$ release did not vary with the age of the cultures. Both cytokines are up-regulated in response to ischemic brain injury (29). The differential effect observed here for the two cytokines is consistent with evidence for differential regulation of IL- $1 \beta$ and TNF- $\alpha$ by the MEK1/2 mediated signaling pathways (30).

Our finding that microglial death is largely apoptotic is consistent with other in vitro studies showing apoptosis in young cultured microglia after LPS overactivation, interferon- $\gamma$ exposure, and opiate administration (31-33). Chromatin condensation was previously described in serum-deprived cultured microglia with comparable levels of cell death to our findings (34). In contrast, few studies have been done on injury-induced release of cytokines by developing microglia. One study (35) found that LPS induced greater IL-6 and IL-1 release with age in microglia and no age-related change in TNF- $\alpha$. However, this study was done in microglia that were cultured from 3- and 24-mo-old rats compared with our neonatal mouse model. Chemokine expression by microglia after hypoxic/ischemic injury showed similar developmental regu- 
lation to our findings in a study describing disappearance of MIP- $1 \alpha$ from rat microglia between P7 and P12 (36).

A number of inflammatory mediators that are released by microglia, including cytokines and nitric oxide, not only affect other cells but also may themselves feedback on microglia. It is possible that the increased TNF- $\alpha$ released by our earlyculture microglia contributed to their tendency to undergo apoptosis after injury. One study found that TNF- $\alpha$ increased the susceptibility of microglia to Fas-ligand-induced apoptosis and was associated with down-regulation of the antiapoptotic genes $\mathrm{Bcl}-2$ and $\mathrm{Bcl}-\mathrm{x}_{\mathrm{L}}$ (37). However, another study implicated microglial production of nitric oxide as the primary autocrine mediator of microglial apoptosis (31). These authors found that inhibition of TNF- $\alpha$ did not affect apoptosis. Regardless of the mechanism, autoregulatory apoptosis to prevent overactivation of microglia may play a role during development of the CNS.

In vivo studies are less clear about the extent of microglial apoptotic cell death after injury. Neonatal piglets that are subjected to hypoxia/ischemia show exclusively apoptotic cell death in immature cerebral white matter (38). Neonatal rats after focal ischemia also demonstrate microglia with DNA fragmentation and expression of the proapoptotic gene Bax (39). In contrast, a study of developing embryonic rat brain found that apoptotic microglia constituted only a very small fraction of the entire microglial cell population until postnatal day 18. The authors postulated that apoptosis does not play a major role in regulating microglial density during development (40). However, with injury, apoptosis may be the primary mechanism of cell death. To the extent that our injury paradigms mimic insults that may occur in the perinatal period, our data support the idea that apoptosis is the predominant pathway for microglial death in the perinatal period.

Several studies demonstrate decreases in caspase 3 levels with development. Murine caspase $3 \mathrm{mRNA}$ and protein levels markedly declined from postnatal day 12 onward $(41,42)$. Similarly, after hypoxic/ischemic injury, levels of caspase 3 declined from postnatal days 7 to 15 in rats (43) with greater necrotic neuronal morphology in older rats compared with a combination of necrotic and apoptotic morphology in immature rats (44). Previous in vitro studies by us and others using whole brain extracts and isolated neuronal cells also found decreased caspase 3 levels with age in culture and after injury $(19,45)$. None of these studies looked specifically at levels of caspase 3 in microglia with development. Our present in vitro measurements did not show a significant change in the percentage of activated caspase 3-positive cells between DIV 2 and DIV 14, in contrast to findings in other cell types with development. We did observe more rapid cell death in early cultures. The lack of a significant difference in apoptotic versus necrotic morphology, percentage of TUNEL-positive cells, and percentage of annexin-positive cells between early and late cultures suggests that the more rapid cell death in early cultures is unlikely to represent a greater component of necrotic cell death.

Human studies also support developmental changes in cytokine production. Some premature infants who were $<28$ wk gestation had very high serum levels of proinflammatory cytokines, including TNF- $\alpha$, IL-1, and IL-6, which then declined during the first postnatal week (46). Underlying inflammatory changes associated with preterm delivery may account for an initial peak in cytokine levels. Neonatal brains with periventricular leukomalacia similarly exhibited high expression of TNF- $\alpha$ and to a lesser extent IL-1 $\beta$ (47). The pattern of cytokine expression in anoxic brains without periventricular leukomalacia also showed significantly lower TNF- $\alpha$ immunoreactivity. Therefore, TNF- $\alpha$ may be an important mediator involved in the pathogenesis of periventricular leukomalacia. It is interesting that in our study, TNF- $\alpha$ was released at higher levels from immature microglia, a factor that might contribute to the propensity for periventricular leukomalacia injury to occur in premature infants.

Our conclusions should be interpreted in the context of a cell culture environment. Longer times in culture may in some respects parallel in vivo changes seen with development, but validation of this possibility must await the identification of markers that change with microglial development. We are not aware of any cellular markers that have been documented to change expression markedly with postnatal development in microglia. Our research suggests that developmental changes do occur in microglia, as has been documented for other brain cell types. Compared with astrocytes and neurons, microglia require a longer duration of injury to achieve the same amount of cell death in young cultures (48). Additional in vivo studies are needed to delineate the importance of apoptotic pathways in microglia with development.

This research explores the response of neonatal microglia to both inflammatory and ischemia-like stimuli as they age in culture. Early-culture microglia are more vulnerable to apoptosis after various insults (SD, GD, and OGD). They also exhibit increased cytokine release that can potentiate ischemic brain injury. Further research on inflammatory changes with development will lead to a better understanding of the role of microglia in perinatal brain injury.

Acknowledgments. We thank Bernadett Romo for help with preparation of the manuscript and Beth Hoyte for help with preparation of the figures.

\section{REFERENCES}

1. Grether JK, Nelson KB 1997 Maternal infection and cerebral palsy in infants of normal birth weight. JAMA 278:207-211

2. Banati RB, Gehrmann J, Schubert P, Kreutzberg GW 1993 Cytotoxicity of microglia. Glia 7:111-118

3. Stoll G, Jander S, Schroeter M 1998 Inflammation and glial responses in ischemic brain lesions. Prog Neurobiol 56:149-171

4. Dawson DA, Martin D, Hallenbeck JM 1996 Inhibition of tumor necrosis factor-alpha reduces focal cerebral ischemic injury in the spontaneously hypertensive rat. Neurosci Lett 218:41-44

5. Nicholas RS, Compston A, Brown DR 2001 Inhibition of tumour necrosis factoralpha $(\mathrm{TNF} \alpha)$-induced NF- $\kappa \mathrm{B}$ p52 converts the metabolic effects of microglialderived TNF $\alpha$ on mouse cerebellar neurones to neurotoxicity. J Neurochem 76:14311438

6. Yrjanheikki J, Tikka T, Keinanen R, Goldsteins G, Chan PH, Koistinaho J 1999 A tetracycline derivative, minocycline, reduces inflammation and protects against focal cerebral ischemia with a wide therapeutic window. Proc Natl Acad Sci USA 96:13496-13500

7. Deng H, Han HS, Cheng D, Sun GH, Yenari MA 2003 Mild hypothermia inhibits inflammation after experimental stroke and brain inflammation. Stroke 34:2495-2501

8. Leviton A, Gilles FH 1984 Acquired perinatal leukoencephalopathy. Ann Neurol $16: 1-8$

9. Back SA, Gan X, Li Y, Rosenberg PA, Volpe JJ 1998 Maturation-dependent vulnerability of oligodendrocytes to oxidative stress-induced death caused by glutathione depletion. J Neurosci 18:6241-6253 
10. Baerwald KD, Popko B 1998 Developing and mature oligodendrocytes respond differently to the immune cytokine interferon-gamma. J Neurosci Res 52:230-239

11. Chock V, Giffard RG 2003 Survival and function of microglia are developmentally sensitive in an in vitro model of neonatal hypoxic/ischemic brain injury. J Perinato 23:578

12. Giulian D, Baker TJ 1986 Characterization of ameboid microglia isolated from developing mammalian brain. J Neurosci 6:2163-2178

13. Sasaki A, Levison SW, Ting JP 1989 Comparison and quantitation of Ia antigen expression on cultured macroglia and ameboid microglia from Lewis rat cerebral cortex: analyses and implications. J Neuroimmunol 25:63-74

14. Yenari MA, Giffard RG 2001 Ischemic vulnerability of primary murine microglial cultures. Neurosci Lett 298:5-8

15. Papadopoulos MC, Koumenis IL, Yuan TY, Giffard RG 1998 Increasing vulnerability of astrocytes to oxidative injury with age despite constant antioxidant defenses Neuroscience 82:915-925

16. Dugan LL, Bruno VM, Amagasu SM, Giffard RG 1995 Glia modulate the response of murine cortical neurons to excitotoxicity: glia exacerbate AMPA neurotoxicity. J Neurosci 15:4545-4555

17. Chan A, Reiter R, Wiese S, Fertig G, Gold R 1998 Plasma membrane phospholipid asymmetry precedes DNA fragmentation in different apoptotic cell models. Histochem Cell Biol 110:553-558

18. Glassford A, Lee JE, Xu L, Giffard RG 2002 Caspase inhibitors reduce the apoptotic but not necrotic component of kainate injury in primary murine cortical neuronal cultures. Neurol Res 24:796-800

19. Xu L, Chock V, Giffard RG 2004 Susceptibility to apoptosis varies with age in cultured murine neurons and astrocytes: changes in gene expression and activity. Neurol Res 26:632-643

20. Yager JY, Thornhill JA 1997 The effect of age on susceptibility to hypoxic-ischemic brain damage. Neurosci Biobehav Rev 21:167-174

21. Sugaya K, Chouinard M, McKinney M 1997 Immunostimulation protects microglial cells from nitric oxide-mediated apoptosis. Neuroreport 8:2241-2245

22. Aspberg A, Tottmar O 1992 Development of antioxidant enzymes in rat brain and in reaggregation culture of fetal brain cells. Brain Res Dev Brain Res 66:55-58

23. Buard A, Clement M, Bourre JM 1992 Developmental changes in enzymatic systems involved in protection against peroxidation in isolated rat brain microvessels. Neurosci Lett 141:72-74

24. Ferriero DM 2001 Oxidant mechanisms in neonatal hypoxia-ischemia. Dev Neurosci 23:198-202

25. Jeohn GH, Kong LY, Wilson B, Hudson P, Hong JS 1998 Synergistic neurotoxic effects of combined treatments with cytokines in murine primary mixed neuron/glia cultures. J Neuroimmunol 85:1-10

26. Hemmer K, Fransen L, Vanderstichele H, Vanmechelen E, Heuschling P 2001 An in vitro model for the study of microglia-induced neurodegeneration: involvement of nitric oxide and tumor necrosis factor-alpha. Neurochem Int 38:557-565

27. Liu B, Gao HM, Wang JY, Jeohn GH, Cooper CL, Hong JS 2002 Role of nitric oxide in inflammation-mediated neurodegeneration. Ann NY Acad Sci 962:318-331

28. Brown GC, Bal-Price A 2003 Inflammatory neurodegeneration mediated by nitric oxide, glutamate, and mitochondria. Mol Neurobiol 27:325-355

29. del Zoppo G, Ginis I, Hallenbeck JM, Iadecola C, Wang X, Feuerstein GZ 2000 Inflammation and stroke: putative role for cytokines, adhesion molecules and iNOS in brain response to ischemia. Brain Pathol 10:95-112

30. Wang H, Xu L, Venkatachalam S, Trzaskos JM, Friedman SM, Feuerstein GZ, Wang X 2001 Differential regulation of IL- $1 \beta$ and TNF- $\alpha$ RNA expression by MEK1 inhibitor after focal cerebral ischemia in mice. Biochem Biophys Res Commun 286:869-874
31. Lee P, Lee J, Kim S, Lee MS, Yagita H, Kim SY, Kim H, Suk K 2001 NO as an autocrine mediator in the apoptosis of activated microglial cells: correlation between activation and apoptosis of microglial cells. Brain Res 892:380-385

32. Liu B, Wang K, Gao HM, Mandavilli B, Wang JY, Hong JS 2001 Molecular consequences of activated microglia in the brain: overactivation induces apoptosis. J Neurochem 77:182-189

33. Hu S, Sheng WS, Lokensgard JR, Peterson PK 2002 Morphine induces apoptosis of human microglia and neurons. Neuropharmacology 42:829-836

34. Koyama Y, Kimura Y, Yoshioka Y, Wakamatsu D, Kozaki R, Hashimoto H, Matsuda T, Baba A 2000 Serum-deprivation induces cell death of rat cultured microglia accompanied with expression of Bax protein. Jpn J Pharmacol 83:351-354

35. Xie Z, Morgan TE, Rozovsky I, Finch CE 2003 Aging and glial responses to lipopolysaccharide in vitro: greater induction of IL-1 and IL-6, but smaller induction of neurotoxicity. Exp Neurol 182:135-141

36. Cowell RM, Xu H, Galasso JM, Silverstein FS 2002 Hypoxic-ischemic injury induces macrophage inflammatory protein- $1 \alpha$ expression in immature rat brain. Stroke 33:795-801

37. Spanaus KS, Schlapbach R, Fontana A 1998 TNF-alpha and IFN-gamma render microglia sensitive to Fas ligand-induced apoptosis by induction of Fas expression and down-regulation of Bcl-2 and Bcl-xL. Eur J Immunol 28:4398-4408

38. Yue X, Mehmet H, Penrice J, Cooper C, Cady E, Wyatt JS, Reynolds EO, Edwards AD, Squier MV 1997 Apoptosis and necrosis in the newborn piglet brain following transient cerebral hypoxia-ischaemia. Neuropathol Appl Neurobiol 23:16-25

39. Benjelloun N, Renolleau S, Represa A, Ben-Ari Y, Charriaut-Marlangue C 1999 Inflammatory responses in the cerebral cortex after ischemia in the P7 neonatal Rat. Stroke 30:1916-1923; discussion 1923-1924

40. Dalmau I, Vela JM, Gonzalez B, Finsen B, Castellano B 2003 Dynamics of microglia in the developing rat brain. J Comp Neurol 458:144-157

41. de Bilbao F, Guarin E, Nef P, Vallet P, Giannakopoulos P, Dubois-Dauphin M 1999 Postnatal distribution of cpp32/caspase 3 mRNA in the mouse central nervous system: an in situ hybridization study. J Comp Neurol 409:339-357

42. Blomgren K, Zhu C, Wang X, Karlsson JO, Leverin AL, Bahr BA, Mallard C, Hagberg H 2001 Synergistic activation of caspase-3 by m-calpain after neonatal hypoxia-ischemia: a mechanism of "pathological apoptosis"? J Biol Chem 276:10191-10198

43. Hu BR, Liu CL, Ouyang Y, Blomgren K, Siesjo BK 2000 Involvement of caspase-3 in cell death after hypoxia-ischemia declines during brain maturation. J Cereb Blood Flow Metab 20:1294-1300

44. Liu CL, Siesjo BK, Hu BR 2004 Pathogenesis of hippocampal neuronal death after hypoxia-ischemia changes during brain development. Neuroscience 127:113-123

45. Yakovlev AG, Ota K, Wang G, Movsesyan V, Bao WL, Yoshihara K, Faden AI 2001 Differential expression of apoptotic protease-activating factor-1 and caspase-3 genes and susceptibility to apoptosis during brain development and after traumatic brain injury. J Neurosci 21:7439-7446

46. Dammann O, Phillips TM, Allred EN, O'Shea TM, Paneth N, Van Marter LJ, Bose C, Ehrenkranz RA, Bednarek FJ, Naples M, Leviton A 2001 Mediators of fetal inflammation in extremely low gestational age newborns. Cytokine 13:234-239

47. Kadhim H, Tabarki B, Verellen G, De Prez C, Rona AM, Sebire G 2001 Inflammatory cytokines in the pathogenesis of periventricular leukomalacia. Neurology $56: 1278-1284$

48. Xu L, Ouyang YB, Giffard RG 2003 Geldanamycin reduces necrotic and apoptotic injury due to oxygen-glucose deprivation in astrocytes. Neurol Res 25:697-700 